\title{
diffMOOC: Differentiated Learning Paths Through the Use of Differentiated Instruction within MOOC
}

\author{
https://doi.org/10.3991/ijet.v12i03.6527 \\ Jihane Sophia Tahiri \\ Mohammed V University in Rabat, Rabat, Morocco \\ jihanesophiatahiri@research.emi.ac.ma \\ Samir Bennani \\ Mohammed V University in Rabat, Rabat, Morocco \\ sbennani@emi.ac.ma \\ Mohammed Khalidi Idrissi \\ Mohammed V University in Rabat, Rabat, Morocco \\ khalidi@emi.ac.ma
}

\begin{abstract}
Diversifying learning practices and situations helps learners to better regulate their learning with deep understanding, which improves learning outcomes. Accordingly, this paper presents our vision of a differentiation system of learning paths within MOOC. Promising beginning point for this vision would be to determine new factors that directly affect the success rate. Then, we introduce the theoretical framework of differentiated instruction, which represents the key component of the proposed system. Finally, we implement some key concepts in differentiation and some techniques for assigning learners into groups in order to differentiate learning paths. The main purpose of the proposed contribution is to optimize learning situations of each learner according to his needs. As a result reducing the proportion of learners in a situation of failure and thereby improving the success rate.
\end{abstract}

Keywords-Massive Open Online Courses, MOOC, differentiated instruction, differentiation, heterogeneity, learner path, dropout rate, decision tree, IMSLIP, learner profile, learner groups, assessment.

\section{Introduction}

Information and Communication Technologies (ICT) are constantly evolving and innovating in terms of services and functionalities. This has led some fields such as medicine, industry, and biology to adopt them. Education is no exception; it is in a position to launch into such experience through which it can lead to new educational opportunities. Indeed, the implementation of ICT in education has led to e-learning, which represents a new form of distance learning. Its purpose is to ensure a distance experience based on open educational content and free access via educational envi- 
ronments. Consequently, e-learning has changed the education as traditionally understood by improving educational methods facing the spatio-temporal constraints [1].

The evolution of ICT has influenced the digital and social habits of learners; it has carried out opportunities and challenges, hence the need to use them in order to meet their different needs. Nowadays, it is possible with MOOC (Massive Open Online Courses). The latter represents a new paradigm that has emerged and became widespread in the field of e-learning. In the most basic definition, the MOOC is an educational model, which is rich in diversified courses, open on a global reach and disposed on the web [2].

The data reveal that the MOOC popularity is increasing which reflect a potential impact in educational sciences and research centers on learning. Consequently, The New York Times has designated 2012 by "The Year of the MOOC" [3]. Although MOOC is not the first or the only way to change education online, it is an opportunity to introduce a new aspect of innovative pedagogy. This revolution continues to be successful through Coursera, Udacity, EdX, which represent the MOOC pioneers. Such platforms provide a relevant and quality educational content with an expertise in a given field. Although the MOOC propose a pedagogical improvement in education, they are subject to limitations, which represent a major challenge. On another matter, given the weight of MOOC, their effectiveness seems undeniable but many issues remain to be resolved.

The high dropout rate provides a recurrent issue often addressed. The research community that investigates MOOC deduced that many factors affect the noncompletion of these courses, we include among others: various categories of registrants, learners' disinterest, lack of time, lack of prerequisites to succeed in a course and the incompatibility between what learners need to know and be able to do [4] [5] [6] [7] [8] [9].

In this paper, we discuss two other factors that negatively affect the MOOC completion rate. We start with learners' heterogeneity. MOOC requires many registrants thus justifying its massive character. This is why they involve heterogeneity since the registrants are so diverse academically, socio-culturally, linguistically, cognitively, and so on. School failure in general and the dropout rate in particular result from what Bourdieu called "indifference to differences" [10]. Not managing this heterogeneity throws in inequalities between learners consequently excluding those in difficulty. The second factor is the diversification of pedagogies and approaches. From the scientific literature, we recognize as a first finding two types of MOOC: xMOOC and cMOOC [2] [11]. The xMOOC philosophy is based on the educational current "behaviorism and cognitivism" and the social component of constructivism [12]. This type provides traditional teaching based on knowledge dissemination and validation of skills. Unlike the cMOOC, it uses the principles of connectivism proposed by George Siemens. MOOC connectivist promotes the implementation of common knowledge within learning community [2]. This diversification of theories would cause confusion and disorientation for learners. As a second finding, designing pedagogical approaches vary depending on the MOOC platform. Generally, they are not aligned with the individual learner needs. 
The main focus of our work is to manage heterogeneity and learners' diversity in MOOC on two levels: (1) individually by taking into account the individual needs of each learner in the most effective way and (2) collaboratively by increasing educational cooperation through groups of learners. To achieve this, we will propose a differentiation system of learning paths within MOOC so as to reduce the proportion of learners in a situation of failure and thereby improve the success rate.

To design our system, we consider some questions that can be summarized as follows: how to differentiate learning paths according to learners' needs? How can we distribute learners into homogeneous groups in order to optimize their learning situations? How can individual and collaborative learning be guaranteed?

The organization of this paper is as follows: first, we focus on the motivation and research objectives (see section 2). Next, we define the theoretical framework of differentiated instruction (see section 3). Then, we present the methodological approach chosen to implement this pedagogy (see section 4). Later, we address our differentiation system of learning paths within MOOC (see section 5). In addition, we synthesize and discuss our proposed work (see section 6). Finally, we expect a conclusion and new paths of future work.

\section{Motivation and Research Objectives}

Our approach relies on the implementation of differentiated instruction within MOOC. The issue that arises: why adopt differentiation as a solution within MOOC? The most important motivation has been on (a) differentiated instruction since it is in line with heterogeneity issue and inequalities rejection. This pedagogy represents a key mechanism for providing learners' development. In addition, it (1) targets learners with learning difficulties (2) identifies their individual characteristics and needs, and (3) it provides an adequate educational solution to acquire knowledge and skills. The other motivate has been on (b) MOOC as a field of application since they sustained educational technologies and enriched learning experiences. Massive courses are in a good position to ensure a multimodal learning using the strengths of differentiated instruction, which enable learners to effectively learn. MOOC and differentiated instruction complement each other and offer a flexible online learning. They represent a techno-pedagogical approach that fit individual and collaborative learning. On the one hand, they focus on learners by providing them adapted paths to ensure their progress. On the other hand, they create collaborative opportunities to help each other and share experiences.

Our goal is to be able to set up a differentiation system that would assist both instructor and learner to better carry out the learning within MOOC. On the one hand, the system provides information and activities of each learner before, during and at the end of the course. These data are used, as a basis, to meet learners' needs according to the appropriate means among a variety of proposed pedagogical practices. On the other hand, the system analyzes the learners' differences and how they are established. Thus, it provides for each learner different learning paths to optimize their learning situations according to their own preferences. 


\section{Theoretical Framework of Differentiated Instruction}

In traditional and distance learning, learners' characteristics are more diverse and heterogeneous. This diversity is reflected in needs, education, interests, skills, sociocultural backgrounds, levels of engagement, learning styles, learning profiles, and so on. Recognizing learners' characteristics is an important step that provides information about learners. The idea of differentiated instruction is based on analyzing learners' differences, taking them into account, and optimizing learning situations.

This section addresses the definition of differentiated instruction and its purpose. Then, it presents the basic levers of differentiation. Finally, it provides a comparison between differentiated instruction and mastery learning to identify points of convergence and divergence.

\subsection{Differentiated Instruction}

Differentiated instruction assumes that learners have different characteristics. According to Robert Burns, these differences constitute the main premises of differentiation, which assert that:

"There are no two learners who learn the same way.

There are no two learners who progress at the same speed.

There are no two learners who are ready to learn at the same time.

There are no two learners who use the same learning techniques.

There are no two learners who solve problems in exactly the same way.

There are no two learners who have the same interest profile.

There are no two learners who are motivated to achieve the same goals" [13].

Differentiated instruction is defined as an organization of pedagogical practices that promotes reporting learners' needs from a learning situation. This pedagogy gives the opportunity to (1) develop the potential to get learners out of a difficult situation (2) provide learning content adapted to learners' preferences (3) cover all the competencies needed (4) direct the learner to the most appropriate learning path, and (5) to make learning situations and activities meaningful.

Learners are more productive and motivated if they have the means that meet their needs. Differentiated instruction ensures the implementation of pedagogical techniques adapted to each learner in order to provide pedagogical responses to a given learning situation. However, it does not seek to modify the content to be taught but to change the way, in which it is taught; that is, the learners' success does not depend on the content itself but on the ability to know when and how to help them apply their knowledge.

Differentiation focuses on the learner as a core element of pedagogical actions. It aims to involve him in the development processes. The main finding of differentiation is adapting the work and not personalizing it permanently [14]. In other words, the instructor must propose an approach that leads learners to progress from the level at which they are in order to keep them in their zone of proximal development (ZPD) [15]. Such pedagogy motivates and encourages the learner to reach its expectations according to its potentials. 
According to the scientific literature, differentiated instruction is interpreted in different ways. The idea of a differentiation began with Célestin Freinet by designating a system of individualization tools, which take into account the learners differences [16]. Formalizing the term "differentiated instruction" is carried out by Louis Legrand, who in turn defined it as an educational necessity that prevents conflicts of differences between learners in the same learning group [17]. From the perspective of André de Peretti, there exist some differentiation derivatives: varied pedagogy and diversified pedagogy. First, the varied pedagogy proposes multiple approaches to the learner, which correspond to his mode of memorization in order to achieve a better learning. Diversified pedagogy uses the diversification of knowledge by multiplying the learning paths [18]. As for differentiated instruction, it represents an educational way that adjusts learning to the learners' diversity. It is based on three principles of differentiation: (1) developing a variety of learning methods and tools (2) providing appropriate responses to learners' expectations, and (3) identifying appropriate practices for a particular learner's need [18] [19]. According to Philippe Meirieu "we should not refer differentiated instruction as a new pedagogical system, but rather as a dynamic to induce in any pedagogical act ... it is necessary for any teaching" [20]. He raises two essential distinctions in differentiated instruction: between differentiation and individualization and between a group of needs and a group of levels. Firstly, differentiation offers a diversified learning adapted to learners' individual specificities while engaging them in collaborative activities but individualization gets the learner working individually according to a predefined work plan [21] [22]. Thereafter, the group of needs is a flexible group constructed over time according to the criteria of learners' distribution. The instructor determines these criteria in advance. Instead, the group of levels is a permanent group during the year that gathers learners at the same level [21] [23]. For Philippe Perrenoud, to differentiate is "to set up a work organization and instructional features that lead to an optimal situation. This organization uses all available resources and works on all parameters in order to establish the most productive situations for each learner" [24].

Basically, differentiated instruction requires an advanced knowledge of learner in order to coach and guide him towards the most appropriate learning path; adding that it organizes different learning situations to cover the recognized needs. The main goal of differentiated instruction is to support constructive learning by proceeding from quantity education to quality education [25]. Furthermore, its intention is focused on individual paths and cooperative learning that ensure a better understanding and acquisition of knowledge. In other words, differentiation combines between individual, intragroup and intergroup work [25] [26]. Differentiation is applied whatever learners' curriculum is since its purpose is to set up an adapted learning, which leads to useful skills in the professional or personal context.

The advantages of differentiated instruction are not limited to that; we include the fact that allows (1) overcoming emotional and social difficulties (2) supporting a high level of learner's engagement (3) developing emotional competencies, and (4) acquiring know-how. 


\subsection{Components of Differentiated Instruction}

Differentiating learning includes basic levers of differentiated instruction, which are: content, process and product. A successful differentiation requires more consistency and progression between its levers to meet learners' needs [27] [28] [29].

Differentiating the Content: The content represents skills and objectives that learners need to learn. Creating content involves a pre-assessment to recognize requirements in relation to the course objectives. The instructor must design different contents around key aims. The purpose of this differentiation is to provide appropriate content for each learner when he proves need.

Differentiating the Process: The process describes how learners take ownership the content. Differentiating the process entails proposing different learning paths using different pedagogical practices. At this situation, learners work on the same goals according to their learning preferences. This differentiation takes place on three levels: before, during and towards the end of learning so that to adequately meet learners needs.

Differentiating the Product: The product or production represents the result of learners learning. These vary in different ways (intelligence, involvement, motivation, collaboration, and so on). Therefore, they must be allowed to differentiate their productions in order to acquire new skills and involving them in the optimal learning situations.

In addition to these three elements of differentiation, some researchers match Philippe Meirieu's idea of managing learners groups in order to address the heterogeneity [20][26]. Given that the purpose of differentiated instruction is heterogeneity, differentiating the structure needed to be considered as the fourth lever of differentiation. For this, it is intended as an initial step, which aims at apportioning learners into learning groups. The organizational criterion of groups should not be permanent but flexible since learners are gradually evolving; consequently, they need to be assigned to another group sharing common characteristics. Differentiating the structure includes personal development. It enables learners to take charge of their own learning from intra-group and inter-group exchanges [26] [30] [31].

For a better illustration, the components of differentiation are summarized in Figure 1 below.

\subsection{Differentiated Instruction Facing Mastery Learning}

Differentiated instruction and mastery learning represent a structured approach that mobilizes scientific practices to design and implement pedagogical strategies. They converge towards a common pedagogical goal: identifying and managing learners' diversity. Consequently, the main issue to which they respond tends to experiences of failure or difficulty [32]. In-depth studies in educational sciences have considered differentiated instruction as a variant of mastery learning [23]. Accordingly, they have points of convergence and divergence. 


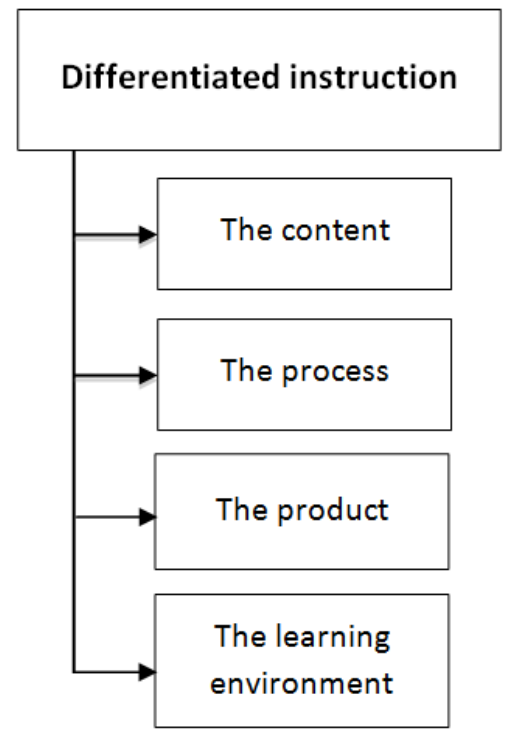

Fig. 1. Components of differentiation

Moreover, Benjamin Bloom introduced the mastery learning since the 1970's [33]. His model is developed around key concepts, namely: differentiated and individualized practices, monitoring progress, evaluation, and feedback [34]. Mastery learning affirms as well as differentiated instruction that most learners are able to acquire competencies and succeed in their learning. Thus, both pedagogies are based on common fundamental elements [35]:

- Diagnosing the learner situation to create his profile and determine his needs;

- Structuring the learning into organized and adapted units according to the learner's characteristics;

- Determining the final and intermediate learning goals;

- Checking learner's progress using formative assessment to address significant deficiencies.

Other common points include the fact that the learner is targeted as a central core since they offer the opportunity to discover and learn from his own means and experiences. Thus, they lead acquiring and mastering core competencies. The individual paths are a basic concept in such pedagogies; they aim to provide the appropriate possibilities of assistance for learners according to their needs.

However, the mastery learning is essentially based on time monitoring which involves cognitive and affective data; that is, mastering a concept depends on the time devoted to learning [35]. The basic principle of such pedagogy is to acquire knowledge aiming to master specific concepts [36]. In this instance, structuring the learning remains stable but mastering time varies from each learner. In contrast to differentiated instruction, mastering a concept is related to learner's preferences and 
needs. It focuses more on "better learning" than on "better teaching". For example, the transition from one learning unit to another is not affected by mastering all concepts since other resources will be incorporated according to proven needs. Furthermore, the formative assessment is a key component for these pedagogies but it designed to be used differently. As regards mastery learning, assessment focuses on curriculum management. However, for differentiated instruction, it focuses on identifying and meeting learning needs [37].

Adopting mastery learning for MOOC does not seem appropriate, for the reason that its benefits are much more different to MOOC requirements. To justify this choose, mastery learning carries out more on the time required to master a concept than on how to master it. This time variation represents a major constraint for its implementation within MOOC. As a result, we have chosen differentiated instruction for its benefits that are aligned with MOOC requirements.

\section{Differentiated Instruction in Action: the Implementing Methodology in MOOC}

In traditional education, the implementation of differentiated instruction represents a major challenge. It requires indeed in-depth skills and good command of the learning environment. Technological innovations have increased rapidly and arisen significant opportunities to support learning experiences. As a result, digital tools prove to be potential catalysts that offer multiple learning paths. They provide innovative practices for designing instruction that supports learners' diversity and their needs. The differentiated instruction receives more benefits but their exploitation remains complicated. Using digital tools, it becomes possible and feasible.

To implement differentiated practices within MOOC, we consider some appropriate concepts and techniques. In this section, we start by identifying the basic types of differentiation. Next, we focus on differentiation approaches in an online device. Finally, we discuss a set of techniques for building learners' groups and their profiles.

\subsection{Basic Types of Differentiation}

Before implementing differentiated practices, it is necessary to distinguish the types of differentiation that exist, we mention as follows: successive differentiation and simultaneous differentiation [23][38][39].

Successive Differentiation: Successive differentiation is a flexible learning process where activities are varied over time and for the same concept. It is programmed in a collective framework. In this differentiation, the success criterion is the same for all learners but the way to acquire knowledge and know-how is diversified. The successive differentiation aims to make available methods, situations or contents for learners in order to progress and succeed in their learning while maintaining collective progress. Moreover, its implementation is easier and more useful to establish.

The operating mode of successive differentiation is shown graphically in Figure 2 below. 


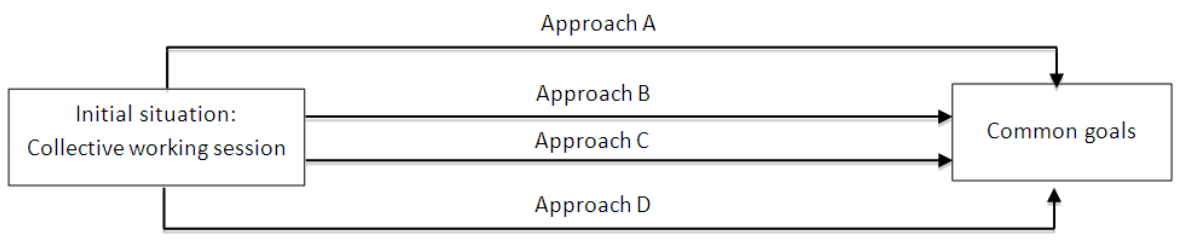

Fig. 2. Successive differentiation

Simultaneous Differentiation: Simultaneous differentiation starts from the idea of simultaneity learning; that is, learners proceed in parallel on different activities according to their characteristics. This differentiation is based on individual learning project as long as it implies that each learner handle work adapted to his needs, at the same time as the other learners. Consequently, delivering a simultaneous strategy does not retain a fixed learning process; it requires developing an individual action plan to achieve a specific objective. Moreover, its implementation is more complex and requires a high degree of precision.

The process of the simultaneous differentiation is shown in the following graphical representation, illustrated in Figure 3.
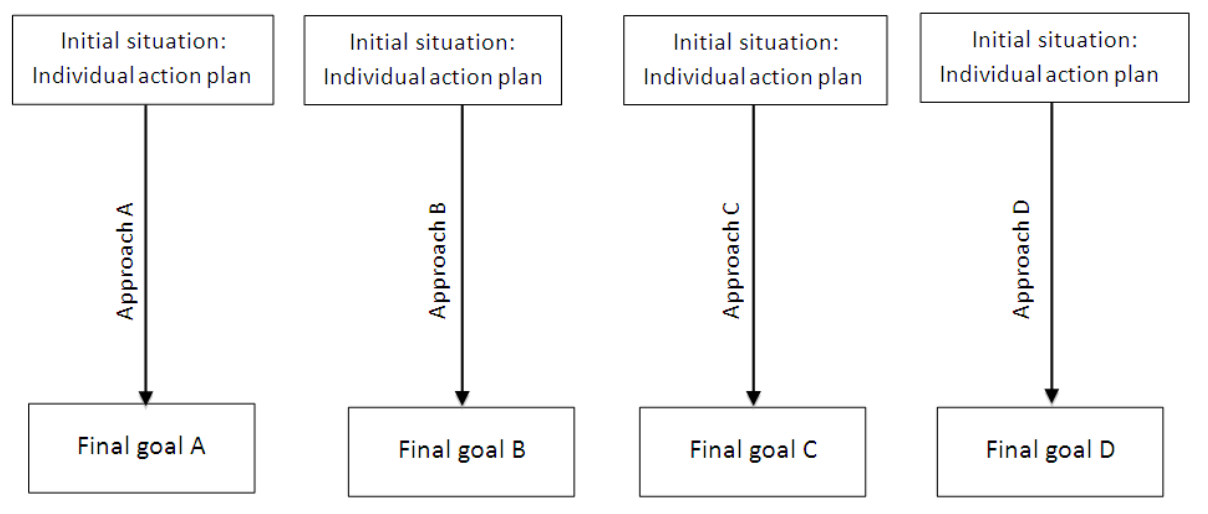

Fig. 3. Simultaneous differentiation

After presenting the specificities of differentiation types, it is clear that each type has advantages and disadvantages. However, if the pedagogical approach fits both types, the most relevant one should be implemented, although it is recommended to combine both to provide complete differentiation. Combining these types lead to a sequencing model of the learning process in 4 steps [21] [22]:

- Diagnosis: it is the triggering step of the differentiation process. The diagnosis of the initial situation makes it possible to gather all the information needed to establish an appropriate work plan. During this step, the instructor uses the successive differentiation by proposing a set of situations and activities to arouse the learners' 
interest and then to determine their needs. A well-established diagnosis will lead to meaningful results without wasting time;

- Knowledge integration: it is characterized by proposing different learning paths. Therefore, acquiring knowledge can be established in learners groups or individually. At this level, the differentiation is simultaneous that aimed to enhance knowledge related to a particular learning;

- Assessment: this process is carried out periodically to analyze and interpret the obtained results compared to the defined objectives. Performing as a learning regulator, it allows decisions and corrective actions to be made. Assessment can be applied in different ways but the most recommended one is the criterion-referenced assessment. Furthermore, it checks learners' performances comparing to competencies defined as criteria;

- Remediation: the pedagogical decisions are taken on the basis of the assessment results. Accordingly, educational methods are introduced as a part of the remediation plan. For remediation step, the differentiation approach used is simultaneous.

\subsection{Applying Differentiated Instruction for e-learning}

Online learning leverages technology for better learning. With this pedagogical trend, adjusting learning process becomes easy and possible by using multiple modalities of technology. Given that educational technologies support differentiation, its design in e-learning is now more feasible. This being so, the e-diff makes reference to the implementation of differentiated instruction in e-learning [40]. Therefore, the challenge is how to establish differentiation logic in an online device. In order to ensure this, it is appropriate to distinguish the different e-diff approaches. They are summarized as follows [40]:

Diffuse Differentiation: It is a way to provide for all learners the same content with multiple learning opportunities. This does not directly address learners' needs but stimulates their attention through diversified approaches. The diffuse differentiation concerns the variation of process not content.

Self-Differentiation: It represents an integrated mechanism enabling learners to choose the content that best meets their needs. The aim is to involve learners in the learning process and consequently build their own learning paths.

Naive Differentiation: The main feature of this approach is delivering automatically and randomly a learning content. Unlike some approaches, learners' needs do not represent the criterion of differentiation. This differentiation approach varies parts of the content in order to motivate the learners to consult them. Unfortunately, its disadvantage is the lack of plans and strategies for differentiation.

Boolean Differentiation: It adjusts the content for learners according to the machine logic. Similarly, this approach reaches through assessment to achieve a framework of rules. Based on the results achieved, the content flow is altered to meet learners' needs.

Model-Based Differentiation: This approach generates ideas on how the content could be differentiated because it is based on a model of didactic practices and data mining techniques. Its ease-of-use represents an important advantage. 
Language-Based Differentiation: Distance learning offers training without spatio-temporal constraints so that learners are heterogeneous in terms of culture, language, competence, and so on. For this, language can constitute differentiation criterion. Language-based differentiation is intended to differentiate content or process according to the language chosen. The content delivery is done either by means of a content repository in different languages or by using translation technologies.

These approaches provide a flexible and diversified way to implement differentiated practices in an online device. Each one meets specific requirements. Given these reasons, choosing the appropriate approaches must be made on the basis of a prior study. It must also take into account both learners' needs and pedagogical strategies. However, designing a differentiation in e-learning does not depend on using a single approach. In the case of a merger between two or more approaches, it is necessary to establish a common link leading to desired objectives.

\subsection{Assessment: A Prerequisite for Differentiation}

Teaching and assessment are two inseparable elements and they act in regulation of the learning process. Therefore, the assessment is an important dimension in evolution and learning strategy plan. It is like an educational action adjuster. According to the scientific literature, the assessment definitions are numerous but share a common purpose. In this point, assessing covers the learning adjusting in order to progress towards educational goals. According to Landsheere, the assessment is an estimate of production, which includes a qualitative and quantitative description considered in a behavior [41]. As for Abernot, assessment is an attempt to judge a competency on the basis of a performance [42].

Recent developments in educational systems have focused on assessment because of its promising benefits over the learning process. Among its positive features we find for example: (1) fostering and stimulating learning (2) supporting learners in their learning according to the objectives to be achieved (3) measuring their real progress (4) regulating learning paths, and (5) reflecting on remediation.

In the context of differentiated instruction, one of its basic principles is based on the assessment and continual adjustments. Promoters of differentiation consider assessment as "a prerequisite for differentiation: it builds a suitable method and appropriately takes place in progress" [21]. Therefore, assessment is a core component in the implementation of differentiated practices.

In differentiated instruction, assessment is addressed for both learner and instructor. First of all, for the learner, it allows him to become aware of his own way of learning, his progress, and his difficulties. Through it, the learner can regulate his learning and learn how to make progress towards its objectives. Then for the instructor, it provides him the opportunity to check the learners' skills and to find out their progressions. Furthermore, the instructor uses it to adjust learning decisions, propose remedial approaches, and improve the quality of teaching.

Diversifying the assessment methods is a concrete example to provide differentiated instruction hence the distinction of several types, namely: prognostic, diagnostic, formative and summative. Although differentiated instruction essentially uses two 
namely: diagnostic assessment and formative assessment. These two types describe the most suitable model for setting up a differentiated instruction.

Diagnostic Assessment: The diagnostic term is generally understood as a first step in developing an educational content. In the differentiation gait, it is an integrated process for learning as it allows defining the initial state of each learner, and putting him in an optimal learning situation using suited means to his preferences.

Diagnostic assessment generally is emphasized in educational practices while fulfilling essential functions. Referring to the scientific literature, we recognize two essential functions [43]: the first one is sort of prevention, which is mainly, concerned setting a new learning sequence. At this level, it aims to adapt teaching to different learner characteristics according to their preferences. Additionally, it makes integration into the learning process as smooth and easy by using diverse methods of teaching. The second function is to study deeply the difficulties that persist in the learner. In this situation, examining learning disabilities involve undertaking remedial actions.

In some respects, the most important strategy of diagnostic assessment is to highlight acquisitions and some difficulties related to learning. In addition, it informs the instructor about the overcoming weaknesses and strengths to sustain. Among its key purposes is (1) bringing out acquired learning (2) producing a qualitative and quantitative description (3) helping to afford the appropriate activities to avoid learning barriers, and (4) placing the learner in his personal dimension facing his competency repository [44] [45].

Early diagnosis is of paramount importance, which often leads to considerable outcomes. In addition, the diagnostic approach must be designed around the primary objectives. For this, the first step of diagnostic assessment is to collect learner's data, which covers his acquisitions, his learning approaches, his attitudes and his preferences. Then link all this up by the learner responses analysis to test his core competencies, and measure his own knowledge in order to build his profile. Ending with the decision-making and a proposition of learning paths in terms of learner's showed needs [46].

Formative Assessment: Formative assessment is an integral part of the learning and monitoring process. It refers to a corrective feedback, which represents a basis for qualitative assessment. This type of assessment appears to show promise for improving consistency learners' achievements. In brief, formative assessment helps identify and fill understanding gaps. Adding that it allows locating where the deviations occur in order to be recovered or settled.

Being the key principle of differentiated instruction, formative assessment is at the heart of teaching and learning, it is enshrined in the problem-solving approach [47]. Its main objective is regulating the learning process for an objective feedback. This is a periodic assessment that occurs at the beginning, the middle and at the end of learning sequences [45]. Philippe Meirieu highlights the regulatory action that formative assessment produces and he stated that: "this regulatory function is essential; it prevents differentiation from being static in a provisional segmentation and, by definition, questionable" [21].

The purpose of formative assessment concerns both learner and instructor. For the learner, it helps to (1) strengthen his motivation (2) support his learning (3) help to 
realize his assets and his gaps, and (4) to develop new skills and learning strategies. For the instructor, it allows to (1) monitor the progress of each learner (2) check the individual control level (3) take corrective pedagogical decisions, and (4) to redirect the activities.

Formative assessment is designed on the basis of three instrumentations: (1) the observation that returns information about the learner and its interactions to define his profile (2) the intervention which allows deciding the necessary help actions in the learning process just after the analysis action, and (3) the regulation that represents the pedagogical strategies in the context of the current activity [47]. The design of formative assessment is done in two ways:

- Normative formative assessment: it compares the learners' results to a standard established by the performance of a reference group [48]. This standard is variable depending on the level of the reference group. The objective of the assessment is to support learners' progress by providing the adapted means to achieve an advanced level.

- Criterion-referenced formative assessment: it checks learner performance against a defined pattern before creating the test. The conception of the model is based on standards that point out skills and targeted performance levels. The criterionreferenced approach aims to assess the degree of learners' knowledge acquisition independently of each other [48].

Both these type of assessment found their way into differentiated educational systems. In terms of advantages given to the baseline assessments, setting up homogeneous learning groups is one. Moreover, assessment processes are not limited only to corrective actions and remediation. They are a good management practice for groups, which act on various criteria. As a result, it makes possible to create adapted and varied devices.

\subsection{Decision Tree to Form Learner Groups}

Clustering learners is a delicate task as long as it has to determine objective criteria in order to obtain homogeneous groups. In education, many clustering methods exist, but the decision tree has been chosen specially for our work. This technique results in a beneficial advantage for the data exploitation. As a result, it allows obtaining a qualitative rather than a quantitative result.

On that point, the decision tree is defined as a very efficient decision-support method for making practical use of the data [49]. Its tree structure makes it flexible, readable, fast and easy to perform; it can be calculated using advanced algorithms. Moreover, this method describes how to distribute individuals into homogeneous groups according to established rules and objectives. It is an iterative method, known as the recursive partitioning.

The decision tree is structured as follows:

- Node: it is defined according to one or more relevant variables, which lead to a division; that is, each node undergoes a dichotomy. As a result, there are two types 
of nodes: an internal node which defines a split of new nodes and an external node which represents a leaf obtained by following a path along nodes.

- Gateway: it represents the link between two nodes. This link corresponds to input rules using variables of the dataset.

- Root: it represents the initial node from which the division begins.

In our paper, the decision tree aims to gather learners into groups according to input rules in order to optimize the learning situations and thus maximize the chances of success. The clustering is carried out in two steps:

- Initial clustering: it defines the starting groups, which are not randomly constructed but instead using diagnostic approach. This latter represents a relevant and thorough step because it determines clustering criteria;

- Improved clustering: it updates the learners' groups when new needs are identified. Based on the formative assessment findings, the initial clustering will be improved for greater coherence and homogeneity.

\subsection{IMS-LIP: the Standardized Learner Profile Definition}

In an e-learning environment, interoperability is a primary need. To meet this challenge, standards have been proposed to assist interaction flow and implementation of the differentiation process. In this section, the emphasis is on defining learner profile and particularly on its standardization.

Each learner has a set of information that identifies and characterizes him. In online learning systems, we use the term "learner profile" instead. It represents a structured model or collection of information about the learner. The model contains not only general information but also information about the characteristics associated with a learner for purposes of [50]:

- Saving and managing learning, objectives, and achievements;

- Promoting learners engagement through learning experiences;

- Identifying learning opportunities for learners.

To ensure a standardized definition of learner profile in e-learning systems, many norms and standards are intended for that purpose. In this paper, we opted for IMSLIP (IMS Learner Information Package) as the appropriate standard for presenting learner information. The specifications of this standard are numerous, some of which meet especially to the requirements of our work. Some of these specifications include those support our choice. Firstly, IMS-LIP contains more details and it is more general; that is, enough information can be introduced to specify the characteristics that must be used in defining learner's profile. Secondly, it ensures an open exchange of learners' information between different Internet-based systems. In relation to this, it supports the interoperability of e-learning environments. Finally, the IMS Learner Information Package specification can be linked to other standards.

Furthermore, IMS-LIP is an IMS Global Standard specification used to present learners' information in a learning experience. In other words, it represents a classical 
approach to structured CV. In this paper, we provide a way to use the IMS-LIP specification to make easier the implementation of differentiated practices. Since the differentiated instruction manages learners' diversity, it uses information about learners and their learning activities to meet their individual needs. In the same way, IMS Learner Information Package is used to specify the characteristics of each learner. For this reason, this standard will be embedded in our contribution in order to allow a more precise definition about how learners learn. In addition to this, the basic structure of the IMS-LIP is rich, which offers more meaningful possibilities for adapting the differentiated practices proposed.

The basic structures of the IMS-LIP are based upon [50] [51]:

- Accessibility: it describes the data regarding learner accessibility (style and learning preferences, language skills, technological orientation, and so on);

- Activity: it represents the learner's manipulations and activities related to a learning experience;

- Affiliation: it represents information about professional organizations belonged;

- Competency: it refers the learner's skills and knowledge;

- Goal: it describes the learner's objectives;

- Identification: it contains the general learner information (first and last name, age, address, telephone number, e-mail, and so on);

- Interests: it represents the learner's hobbies;

- Qualification, Certification and License (QCL): it represents all the learner's diplomas, certificates, and training;

- Relationship: it describes the relationships that may exist between the basic elements of the IMS-LIP structure;

- Security: it represents the learner's confidential data (passwords, security codes);

- Transcript: it summarizes the learner's results.

\section{5 diffMOOC: Differentiation System of Learning Paths within MOOC}

Engaging learners in pre-designed learning situations without considering their needs is a major barrier to success. However, it is necessary to define a flexible pedagogical framework that aligns, at the same time, with learning objectives and preferences of each learner. The aim of our research is to design a structured and structuring organization that allows a gradual evolution of the learning process within MOOC, from point of view of learner and instructor.

Consequently, we opted for the differentiated instruction as a basis for remedying the recurrent problem of $\mathrm{MOOC}$, which is the dropout rate. Meeting perfectly to the particular requirements of these courses, the implementation of differentiated instruction represents the major rigor. Our contribution is designed to manage learners' heterogeneity and to standardize the pedagogical design of the massive courses.

In what follows, we propose a differentiation system of learning paths within MOOC to maximize the chances of success. This system aims (1) to meet the needs 
of various learners (2) providing suitable means and working arrangements (3) creating multiple learning paths, and (4) ensuring that all learners have the skills and knowledge they need to reduce dropout.

To achieve this goal, this section includes (1) the approach used to achieve the system and (2) its operating mode.

\subsection{Implementing the Proposed Differentiation System}

In our contribution, we propose a regular pedagogical framework that organizes the learning process within MOOC. It focuses on differentiated paths, which lead to the same objectives for all learners. In order to develop the proposed system, we used some concepts of differentiated instruction, standards for defining the profile of each learner, and in addition techniques for managing learner groups.

The design of the proposed system involves several steps. We synthesize them as follows:

Diagnosis of the Initial Situation: This step identifies the core around which differentiated practices will be proposed. It is through which learner's prerequisites are verified. Diagnosis is an initial and essential step as long as it offers a strategic and organizational vision to adapt the means and the working arrangements according to the needs expressed.

Learner Profile Definition: The learner profile provides general information about each learner (identity, activities, interests, intellectual preferences, learning styles, and so on). In terms of our system, we are led to create learners profiles to use them in the differentiation process. The profile definition will be based on the IMSLIP standard.

Arranging Learner Groups: Being a component of differentiated instruction, it was necessary to set up the learners' structuring. For this reason, the proposed system aims to gather learners into homogeneous groups especially into groups sharing the same characteristics. The construction of learners groups is carried out on the basis of determined rules with the decision tree.

\subsection{Proposed Differentiation System Functioning}

Having set out the steps involved in our differentiation system of learning paths, it is time to describe its operating mode. For this purpose, the functional process of the proposed system is presented in the textual form as follows, while Figure 4 illustrates its graphical representation:

- The system begins as soon as a learner is enrolled for MOOC. At registration, the learner receives a test whose answers are scored on a numerical scale. This test defines the execution of the learning process;

- On the basis of the provided answers, the system verifies the initial situation of each learner. If he completes the required prerequisites, he can enroll in the course; if not the system will recommend to him other resources. It should be noted that 
learners who do not meet the required prerequisites choose to take course, they will be assigned to a group whose results will not be taken into the final statistics;

- Thereafter the learner profile is defined according to IMS-LIP standard in the profiles database. The profile definition provides full traceability on learners' characteristics and it supports it in implementing differentiated practices;

- The learner profile is not initiated by stereotypes but based on the diagnostic assessment results. The profile evolves progressively according to learner's performances after each formative assessment;

- The next step is to gather learners into homogeneous groups. The clustering is carried out on the basis of the rules determined with the decision tree. These rules can be defined systematically through the system or manually by the instructor;

- By analyzing needs and preferences of each group, the system provides learning experience they need. It will provide the learners with individual learning paths according to specific objectives while integrating the pooling of learning process;

- As a part of the chosen e-diff approach, the design of learning situations considers an adjustment of content, process and product;

- Successful differentiation requires a formative observation, which compares each learner to the learning objectives. At this level, a formative assessment is necessary since it makes it possible to follow learners' progress by reviewing their works on a regular basis;

- Based on the formative assessment results and learners' manipulations, corrective actions will be taken to adjust the working arrangements. As a result, the learner profile will be updated and the distribution of learners in groups will be improved;

- The formative assessment process, the updating of learner profile and groups is carried out periodically throughout the MOOC;

- Certificated assessment is the last step of MOOC. However, the objective is not to obtain a single homogeneous group with common characteristics but to increase the proportion of learners completing the courses and thereby improving the success rate.

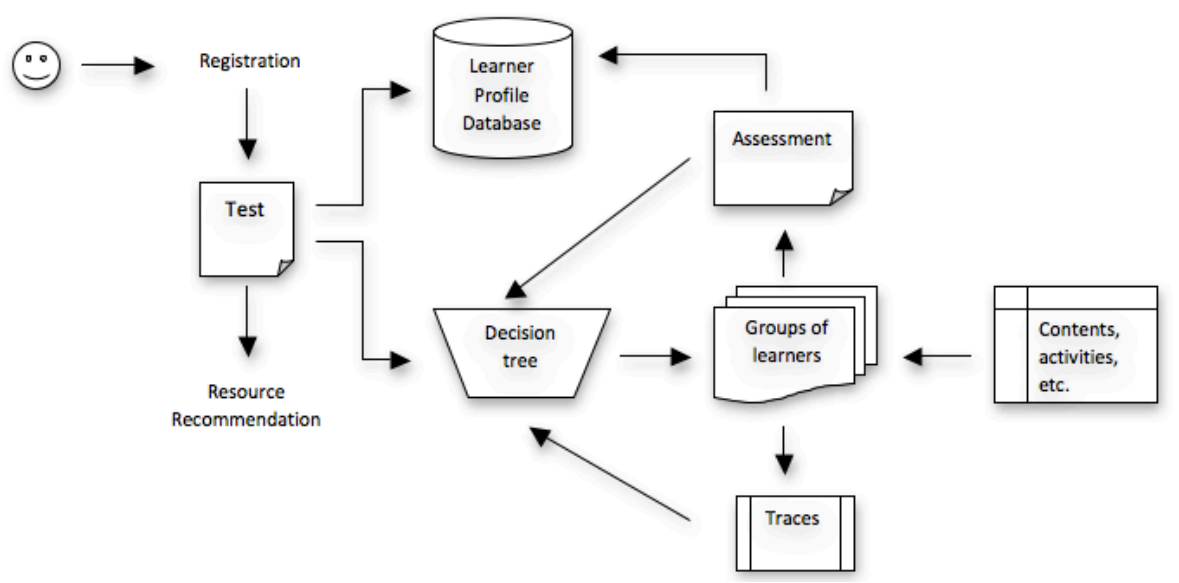

Fig. 4. Differentiation system of learning paths 


\section{Discussion}

The success rate within MOOC is known notoriously to be low worldwide. That is due to several factors, including two of which are discussed in our paper: learners' diversity and discord of the approaches and education methods adopted. In light of these reasons, this discussion paper proposes a differentiated approach aimed for all learners to assist them step-by-step in order to succeed in their learning.

Using technological affordances to establish differentiated instruction, create the potential for a new evolution phase of learning enhanced by technology. For this reason, our contribution consists of setting up a differentiation system of learning paths within MOOC to stand the best possible chance of success.

The proposed system ensures the transition from a classical teaching logic to a coaching logic. This creates a dynamic to ensure a meaningful learning by putting the learner at the center of his own learning. The aim is not communicating knowledge but focusing the learner on the essential to feel interest and need. Among the aims of the system is to make pedagogical changes in order to help learners reaching the highest possible level of their potential. However, it is necessary to propose pedagogical practices that ensure keeping learners in their zone of proximal development (ZPD) and not presenting an obstacle to them.

Using this contribution, it is possible to combine individual and collaborative learning in the same approach. The aim was to find a balance between the autonomy of each learner and the cooperation. In other words, it ensures meaningful situations within their reach. To this end, we believe that our differentiation system of learning paths uses perfectly the fundamental elements of differentiated instruction as well as standards and techniques for managing groups to provide a complete and successful learning for all learners.

\section{Conclusion}

Differentiated Instruction has been the subject of interesting research as it has attracted the researchers' interests in educational sciences. Indeed, it aims to control the distance between learners' differences and one of the main issues for school failure and inequalities, which is learners' heterogeneity. Our work is focused mainly on implementing differentiated instruction in the MOOC context. Thus, the purpose of the paper was to improve the proportion of learners completing courses and implicitly improving the success rate. Initially, it was necessary to identify the factors affecting the success rate, which led choosing the differentiated instruction as a solution and fundamental basis of the contribution. In addition, we have presented the general differentiation framework more specifically its definition, its key levers and its relationship with mastery learning. The introduction of differentiated instruction in the MOOC context was a major challenge. Thus, we have put forward the necessary technical approaches for this purpose. In the end, we have proposed a differentiation system of learning paths adapted to MOOC. The system goal was to (1) structure learning process according to learners' preferences (2) result in an interesting homo- 
geneity of the group (3) support the instructor in decision-making, and (4) to better ensures that each learner carries out his learning within MOOC.

For future research, we are looking to complete a depth analysis by studying learners' interactions with various course components. Furthermore, individual needs and learners' preferences could be better addressed by incorporating data analysis technologies for an optimal identification of appropriate learning paths. In other future experiments, we plan to model and implement the system across multiple platforms hosting MOOC.

\section{$8 \quad$ References}

[1] Tahiri, J.S., Bennani, S., \& Idrissi, M. K. (2015, October). Using an analytical formalism to diagnostic and evaluate Massive Open Online Courses. In 2015 10th International Conference on Intelligent Systems: Theories and Applications (SITA) (pp. 1-6). IEEE.

[2] Tahiri, J.S., Bennani, S. and Khalidi Idrissi, M. (2014). MOOC... A Mature Collaborative Workspace: Issues of Success Rate. Proceeding of the 2nd Francophone Conference on Collaborative Systems (SysCo'14), Hammamet-Tunisia (Original language is French).

[3] Guillemet, P. (2014). Panoramic MOOC: Distances and Mediations of Knowledge, available on: http://dms.revues.org/532 (accessed: November 2016) (Original language is French).

[4] Rivard, R. (2013). Measuring the MOOC Dropout Rate. Inside Higher Ed, vol. 3.

[5] Kolowich, S. (2013). Coursera Takes a Nuanced View of MOOC Dropout Rates. The Chronicle of Higher Education.

[6] Clow, D. (2013). MOOC and the Funnel of Participation. In Proceedings of the Third International Conference on Learning Analytics and Knowledge, p. 185-189, ACM. https://doi.org/10.1145/2460296.2460332

[7] Conole, G.G. (2015). MOOC as Disruptive Technologies: Strategies for Enhancing the Learner Experience and Quality of MOOC. Revista de Educación a Distancia, no 39.

[8] Onah, D.F., Sinclair, J. and Boyatt, R. (2014). Dropout Rates of Massive Open Online Courses: Behavioural Patterns. EDULEARN14 Proceedings, p. 5825-5834.

[9] Noddings, N. (2010). Differentiate don't Standardize. Education Week, vol. 29, no 17, p. 29-31

[10] Bourdieu, P. (1966). The Conservative School: Inequalities in Front of School and Culture, French Journal of Sociology, no 3, p. 325-347 (Original language is French).

[11] Siemens G. (2012) MOOC is Really a Platform, available on: http://www.elearnspace.org/ blog/2012/07/25/moocs-are-really-a-platform/ (accessed: November 2016).

[12] Yousef, A.M.F., Chatti, M.A., Wosnitza, M. and Schroeder, U. (2015). A Cluster Analysis of MOOC Stakeholder Perspectives. Revista de Universidad y Sociedad del Conocimiento, vol. 12, no 1, p. 74-90. https://doi.org/10.7238/rusc.v12i1.2253

[13] Burns, R. (1971). Methods for Individualizing Instruction. Educational Technology, vol. 11 , no 6, p. 55-56.

[14] Tahiri, J. S., Bennani, S., \& Idrissi, M. K. (2016, December). An assessment system adapted to differentiated learning within Massive Open Online Courses using psychometric testing. In Information Technology Based Higher Education and Training (ITHET), 2016 15th International Conference on (pp. 1-7). IEEE.

[15] Gillig J.M. (1999). Differentiated Instructions, Paris, Boeck and Larcier's Editions (Original language is French). 
Paper-diffMOOC: Differentiated Learning Paths Through the Use of Differentiated Instruction within...

[16] Freinet, C. (1973). Freinet's Techniques of the Modern School (Original language is French).

[17] Legrand, L. (1986). Educational Differentiation. Paris, Scarabée's Editions. p. 37-38 (Original language is French).

[18] De Peretti, A. (1985). Outline of a Theoretical Foundation for Differentiated Pedagogy. Sèvres's Friends, p.117 (Original language is French).

[19] De Peretti, A. (1987). Differentiated Organization of Education and Allocation of Multiple and Complementary Roles (Original language is French).

[20] Meirieu, P. (1989). Differentiating Pedagogy. Educational books (Original language is French)

[21] Meirieu, P. (1996). Differentiated Instruction: Enclosure or Openness? (p. 1-32). Philippe Meirieu's website, available on: http://www.meirieu.com/ARTICLES/pedadif.pdf (accessed: November 2016) (Original language is French).

[22] Booklet: Personalization of Learning Paths and Situations, INRP, 2008 (Original language is French).

[23] Robbes, B. (2009). Differentiated Instruction: Historical, Problematic, Conceptual Framework and Methodology of Implementation. Philippe Meirieu's website, History and Actuality of Pedagogy (Original language is French).

[24] Perrenoud, P. (2000). Differentiated Instruction: from Intentions to Action (Original language is French).

[25] Looi, C.K., Wong, L.H., So, H.J., Seow, P., Toh, Y., Chen, W and Soloway, E. (2009). Anatomy of a Mobilized Lesson: Learning my Way. Computers \& Education, vol. 53, no 4, p. 1120-1132. https://doi.org/10.1016/j.compedu.2009.05.021

[26] Przesmycki, H. (2004). Differentiated Instruction, Hachette Education's Editions (Original language is French).

[27] Kahn, S. (2010). Differentiated Instruction: Update on Education Research (Original language is French).

[28] Denise, D.F. Diversity of Learners, Differentiated Instruction, and e-learning, available on: http://www.kaplanuniversity.edu/public-service/articles/elearning.aspx (accessed on November 2016).

[29] Hall, B. (2009). Differentiated Instruction.

[30] Perrenoud, P. (1996). Differentiated Instruction. Faculty of Psychology and Education Sciences, University of Geneva (Original language is French).

[31] Laskaris, J. (2015). 5 Tips for Applying Differentiated Instruction in eLearning. Talent LMS Blog, available on: https://www.talentlms.com/blog/5-tips-for-applying-differenti ated-instruction-in-elearning/ (accessed: November 2016).

[32] Shafie, N., Shahdan, T.N.T. and Liew, M.S. (2010). Mastery Learning Assessment Model (MLAM) in Teaching and Learning Mathematics. Procedia-Social and Behavioral Sciences, vol. 8, p. 294-298. https://doi.org/10.1016/j.sbspro.2010.12.040

[33] Bloom, B. (1971). Mastery Learning: Theory and Practice, p. 47-63.

[34] Kularbphettong, K., Kedsiribut, P. and Roonrakwit, P. (2015). Developing an Adaptive Web-based Intelligent Tutoring System Using Mastery Learning Technique. ProcediaSocial and Behavioral Sciences, vol. 191, p. 686-691. https://doi.org/10.1016/j.sbspro. 2015.04.619

[35] Norma, Z. Helping Students in Difficulty. Research project, University of Saint-Esprit de Kaslik, Lebanon (Original language is French).

[36] Amiruddin, M.H., Samad, N.A. andOthman, N. (2015). Investigation Effects of Mastery Learning Strategy on Entrepreneurship Knowledge Acquisition among Aboriginal Stu- 
Paper-diffMOOC: Differentiated Learning Paths Through the Use of Differentiated Instruction within...

dents. Procedia-Social and Behavioral Sciences, vol. 204, p. 183-190. https://doi.org/10.1016/j.sbspro.2015.08.131

[37] Raynal, F. and Rieunier, A. (2014). Pedagogy, Dictionary of Key Concepts: Learning, Training, Cognitive Psychology. Issy-les-Moulineaux: ESF (Original language is French).

[38] Florence, S.L. (2013). Differentiated Instruction, Active and Cooperative Pedagogies. University of Aix-Marseille (Original language is French).

[39] Cornet, B. (2005). Differentiated Instruction (TFE), available on: http://www.enseignement.be/index.php?page $=23827 \&$ do id $=2456$ (accessed: November 2016) (Original language is French).

[40] Gawande, V. (2011). Differentiated eLearning: The Possible Approaches. In the International Information Systems Conference (iiSC), Sultan Qaboos University, Muscat, Sultanate of Oman, p. 212.

[41] Landsheere, G. (1992) Assessment Dictionary and Education Research. 2nd edition of University Press of France (Original language is French).

[42] Abernot, Y. (1993). School Assessment in J. Houssaye, Pedagogy: Today Encyclopedia. Paris: ESF's Editions (Original language is French).

[43] Grégoire, G. (1996). Assessing Learning: the Contributions of Cognitive Psychology. Boeck Superior Editions (Original language is French).

[44] Robichon, J. (2007). A Diagnostic Assessment Booklet Built and Shared for All, available on: http://www.educ-revues.fr/CEPS/AffichageDocument.aspx?iddoc $=38400$ (accessed: November 2016). (Original language is French).

[45] Hadji, C. Assessment, Rules and Intention Tools. Paris: ESF Publisher, available on: http://sites.estvideo.net/gfritsch/doc/rezo-cfa-308.htm\#S4 (accessed: November 2016) (Original language is French).

[46] Cardinet, J. (1988). Assessing Student Work. Boeck's Editions, 2nd edition. (Original language is French).

[47] Perrenoud, P. (2001). The Assessment Challenges in the Context of Multi-Year Learning Cycles, available on: http://www.unige.ch/fapse/SSE/teachers/perrenoud/php main/ php 2001/2001 22.html (accessed: November 2016) (Original language is French).

[48] Brinton, C., Chiang, M., Jain, S., Lam, H., Liu, Z. and Wong, F.M.F (2014). Learning about Social Learning in MOOC: from Statistical Analysis to Generative Model. IEEE Transactions on Learning Technologies, vol. 7, no 4, p. 346-359. https://oi.org/10.1109/ TLT.2014.2337900

[49] Santos, F. (2015). Decision Tree (Original language is French).

[50] Laroussi, M. (2012). Extending IMS-LIP to Support Pervasive Learning (Original language is French).

[51] Available on: http://www.imsglobal.org/profiles/index.html (accessed: November 2016).

\section{Authors}

Jihane Sophia TAHIRI, Engineer degree in computer science in 2013 from National School of Applied Sciences (ENSA), Safi-Morocco. She is PhD student in computer science at Mohammadia School of Engineers (EMI), Mohammed V University in Rabat, av Ibn Sina postbox 765, Agdal-Rabat, Morocco. She is a member of RIME Team (Networking, Modeling and E-learning) in LRIE Laboratory (Research in Computer Science and Education Laboratory), Rabat-Morocco. Areas of interest: 
MOOC, e-learning, technologies in learning. (Email: jihanesophiatahiri@research.emi.ac.ma)

Samir BENNANI, Deputy director at Mohammadia School of Engineers (EMI), Mohammed V University in Rabat, av Ibn Sina postbox 765, Agdal-Rabat, Morocco. In addition, he is a pedagogical tutor and a professor at the computer science department at EMI. (Email: sbennani@emi.ac.ma)

Mohammed KHALIDI IDRISSI, Assistant chief of the computer science department at Mohammadia School of Engineers (EMI), Mohammed V University in Rabat, av Ibn Sina postbox 765, Agdal-Rabat, Morocco. He is also a pedagogical tutor and a professor at the computer science department at EMI. (Email: khalidi@emi.ac.ma)

Article submitted 15 December 2016. Published as resubmitted by the authors 26 January 2017. 